\title{
The prevalence and predictors of cognitive impairment in type 2 diabetic population of Punjab,
} India

\author{
Shallu Khullar, Gurpreet Kaur, Harjot Dhillon, Ritu Sharma, Kanchan Mehta, Monica Singh, Puneetpal Singh \\ Department of Human Genetics, Punjabi University, Patiala, Punjab, India
}

\section{A B S T R A C T}

Background: The present cross sectional study was carried out on 516 subjects with type 2 diabetes from a tertiary health care hospital to identify the prevalence and predictors of cognitive impairment in diabetes. Materials and Methods: Cognitive impairment was tested using Mini Mental Scale Examination (MMSE), Trail making tests-A and B (TMT-A and TMT-B). Efficiency of these tests to diagnose cognitive impairment was analysed using reliability index (Cronbach's $\alpha=0.82$ ), which ruled out any internal inconsistency. Of the study participants, I 74 (33.73\%) met the criteria for cognitive impairment and 342 (66.27\%) were having normal cognition. Out of I74, I56 diabetic subjects (89.65 percent) were not diagnosed for neurocognitive impairment prior participation. Results: Cognitive impairment was observed to be strongly associated with being a woman $(P<0.00 \mathrm{I})$, divorced or separated $(P=0.007)$, sedentary life style $(P=0.00 \mathrm{I})$, smoking $(P<0.00 \mathrm{I})$, drinking alcohol $(P<0.00 \mathrm{I})$, systolic blood pressure $>120 \mathrm{mmHg}(P=0.003)$, triglycerides $(\mathrm{TG})>\mathrm{I} 50 \mathrm{mg} / \mathrm{dl}(P=$ $0.00 \mathrm{I})$, high density lipoprotein $<40 \mathrm{mg} / \mathrm{dl}(P=0.00 \mathrm{I})$, statin use $(P=0.009)$, waist hip ratio in both males and females $(P=0.00 \mathrm{I})$, glucose levels $>125 \mathrm{mg} / \mathrm{dl}(P=0.005)$ and duration of diabetes $>2$ years upto 10 years and more than 10 years $(P=0.00 \mathrm{I})$ in univariate testing. In multivariate logistic regression model, being a woman was an independent risk factor for cognitive decline, which is two fold higher (OR $2.0095 \% \mathrm{Cl}$ I.25-3.20, $P=0.004$ ) than being a man. Other risk factors like glucose levels $>125 \mathrm{mg} / \mathrm{dl}$, systolic blood pressure $>120$ $\mathrm{mmHg}$, sedentary life style and duration of diabetes $>10$ years emerged as independent predictors of cognitive impairment in diabetes. Conclusion: In conclusion, the present study revealed that higher prevalence of cognitive impairment in diabetes is evident in population of Punjab, especially in women and majority of these patients remain undiagnosed for it.

Key words: Cognition, India, prevalence, Punjab, type 2 diabetes

\section{INTRODUCTION}

The alarming prevalence of diabetes in its global perspective has attracted the attention of researchers to investigate the factors that are associated with it and may worsen its pathology. Several risk factors of type 2 diabetes (T2DM) such as endothelial dysfunction, obesity, dyslipidemia, hypertension, hypothalamus-pituitary-adrenal axis (HPA

\begin{tabular}{|l|l|}
\hline \multicolumn{2}{|c|}{ Access this article online } \\
\hline Quick Response Code: & Website: \\
\hline & www.josh.net \\
\hline & \\
\hline
\end{tabular}

axis) abnormalities, and underlying inflammation impact negatively on brain. ${ }^{[1]}$ Some studies have suggested that T2DM impinge upon cognitive domains, especially verbal memory, attention or processing speed, psychomotor ability, and executive functions. ${ }^{[2-4]}$ Duration of diabetes has also been observed to be related with cognitive decrements This is an open access article distributed under the terms of the
Creative Commons Attribution-NonCommercial-ShareAlike 3.0
License, which allows others to remix, tweak, and build upon the
work non-commercially, as long as the author is credited and the
new creations are licensed under the identical terms.

For reprints contact: reprints@medknow.com

How to cite this article: Khullar S, Kaur G, Dhillon H, Sharma R, Mehta K, Singh $\mathrm{M}$, et al. The prevalence and predictors of cognitive impairment in type 2 diabetic population of Punjab, India. J Soc Health Diabetes 2017;5:47-53.

Corresponding Author: Dr. Puneetpal Singh, Department of Human Genetics, Punjabi University, Patiala - 147 002, Punjab, India. E-mail: singh.puneet@rediffmail.com 
such as immediate verbal recall, delayed verbal recall, and abstract reasoning. ${ }^{[5]}$ However, conclusions vary depending on the sampling strategy, study design, tests for cognition used, diabetes severity, and co-existing morbidities. ${ }^{[6,7]}$ Several association pathways of T2DM and cognitive decline have been established whereby some studies reported the association of diabetes with Alzheimer's ${ }^{[8]}$ and vascular dementia, ${ }^{[9]}$ and other studies reported its association with hypertension ${ }^{[10]}$ and stroke. ${ }^{[11]}$ Another form, i.e., type 3 diabetes results with an insulin resistance in the brain causing Alzheimer's and has molecular and biochemical features encompassing both type 1 diabetes mellitus and T2DM. ${ }^{[12]}$ Nevertheless, these studies have shown common manifestations of these pathways that contribute to cognitive impairment.

The possible link of T2DM with cognitive performance is intricate and remains unforeseen as other factors including age, socio-economic status, marital status, level of education, and other comorbidities also influence cognitive function. To understand the influence of diabetes on cognitive impairment, the present study was designed to examine the prevalence and predictors of neurocognitive impairment in type 2 diabetic population of Punjab, India.

\section{MATERIALS ANd MethodS}

The present cross-sectional study comprised 516 T2DM subjects who attended endocrinology outpatient department (OPD) of Government Medical College and Hospital (GMCH), Patiala, Punjab, India. A total of 1098 patients were screened and 1015 qualified for inclusion according to diagnostic criteria given by American Diabetes Association. ${ }^{[13]}$ After following stringent inclusion-exclusion criteria, 516 diabetic subjects were included in the present research. The inclusion criterion was consenting T2DM patients belonging to Punjab. Exclusion criteria was subjects not from Punjab or had any other neurological conditions such as stroke, Alzheimer's disease, vascular dementia, Parkinson's disease, epilepsy or head injury, cardiovascular diseases such as hypertension, hypotension, or atherosclerosis and psychiatric disorders; depression, alcohol dependence, drug dependence, and use of antidepressant or antipsychotic medications [Figure 1]. All patients gave their written consent prior to participation, and the study was approved by Institutional Ethical Committee.

Patients were assessed for cognitive impairment by using the Mini Mental State Examination (MMSE), ${ }^{[14]}$ a standard version 30-point questionnaire used to screen arithmetic, language use, memory, and orientation (basic motor skills). It is a validated measure for evaluating cognitive decline, whereby MMSE score of $<23$ has sensitivity of $81.3 \%$ and specificity of $60.2 \% .^{[15]}$ The scoring by MMSE can be influenced by the effect of age and education level. To avoid any bias, present data were well matched for age and education status $(P>0.05)$. Furthermore, other tests were

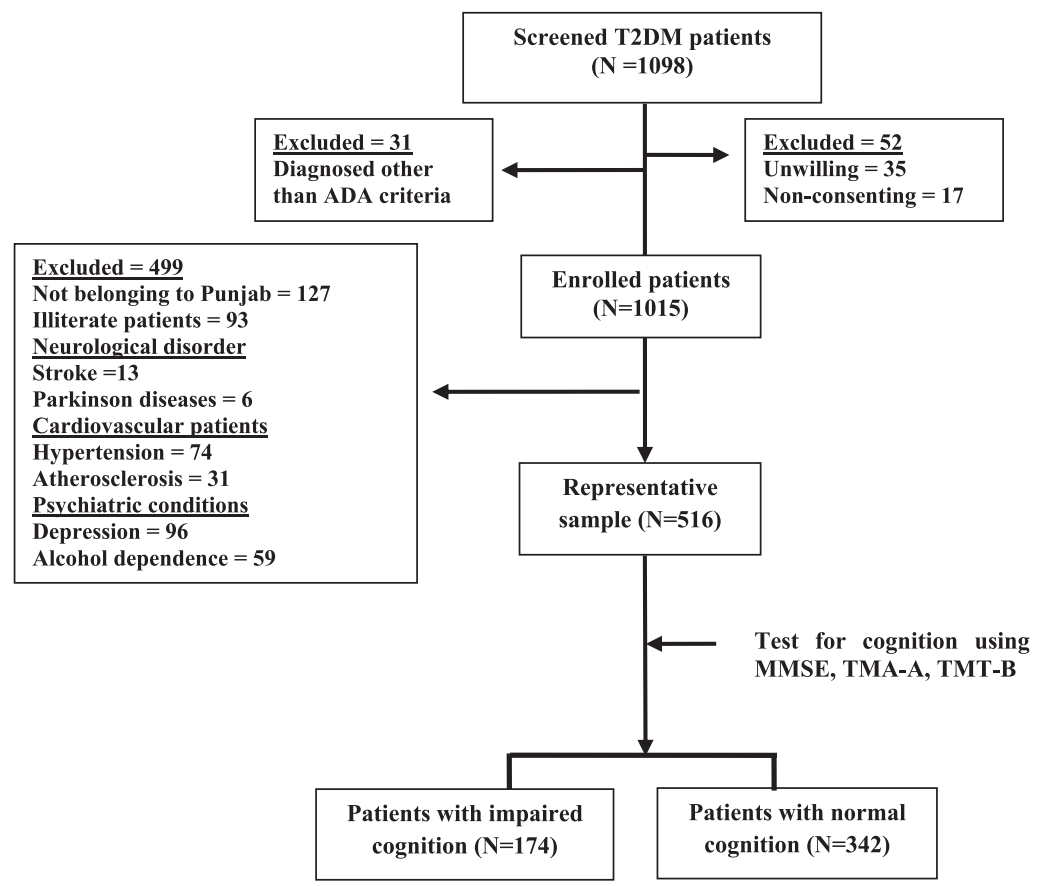

Figure 1: Showing data collection protocol after following stringent inclusion and exclusion criteria 
also used to screen subjects for cognitive decline such as trail making test-A (TMT-A for attention and information processing speed with visuomotor component) and trail making test-B (TMT-B for visual attention) ${ }^{[16]}$ along with MMSE.

\section{Definition of risk variables}

Socio-economic status was evaluated according to the updated version of Kuppuswamy and Pareek scale ${ }^{[17]}$ and categorized according to per capita per month income in rupees, $\leq 10,000$ (low-income group), 10,000-50,000 (middle-income group), and >50,000 (high-income group). Physical activity was determined on the basis; if subject was doing at least $30 \mathrm{~min}$ of aerobic exercise/walk, he/she was considered active otherwise sedentary. Aerobic walking means consistent walk of $1 \mathrm{~km}$ in 13 min or less. Lipid levels, duration of diabetes, statin use, and glucose levels were noted down from their medical records. Information regarding marital status, education level, smoking, and drinking alcohol was recorded by interviewing them. Anthropometric measurements such as height and weight were measured and body mass index (BMI) was calculated according to Quetelet equation (BMI = weight in kilograms/height in meters squared). For waist-hip ratio, waist circumference was measured at the midpoint between the lower margin of ribs and the superior border of the iliac crest. Hip circumference was measured around the widest portion of the buttocks. Systolic blood pressure (SBP) and diastolic blood pressure were noted down as a mean of two tests conducted after an interval of $3 \mathrm{~min}$ in sitting position after 15 min of rest.

\section{Statistical analysis}

Data are presented as mean \pm standard deviation, numbers or percentages, and interquartile range is given for skewed data. The difference between the groups was examined using Chi-square test for categorical variables and Student's $t$-test for continuous variables. The internal consistency reliability for MMSE, TMT-A, and TMT-B was checked using Cronbach's alpha. A linear regression was applied to investigate the association between cognitive decline and risk variables (general linear model procedure). Those variables which showed linear relationship with the dependent variable in univariate testing were further included in the multivariate logistic regression analysis (backward stepwise) to identify independent association of the significant variables. The significance was checked at $5 \%$ level, but for multiple comparisons, Bonferroni correction was applied accordingly.

\section{RESULTS}

The present study involved 516 adult T2DM subjects of Punjab. Out of which, 289 (56.01\%) were men and 227 (43.99\%) were women. One hundred and seventy-four $(33.73 \%)$ met the criteria for impaired cognition, whereas 342 (66.27\%) were having normal cognition. The mean age of diabetic subjects was $47.79 \pm 10.18$. It is noteworthy that out of $174,89.65 \%$ of the diabetic subjects were undiagnosed for neurocognitive impairment before participation in the present study. Univariate analysis of the variables [Table 1] showed that women were approximately 2 times more vulnerable for cognitive

\begin{tabular}{|c|c|c|c|c|c|}
\hline \multicolumn{6}{|c|}{ Diabetic subjects $(N=516)$} \\
\hline Variables & $\begin{array}{c}\text { Impaired cognition } \\
N(\%) \\
174(33.73)\end{array}$ & $\begin{array}{c}\text { Normal cognition } \\
N(\%) \\
342(66.27)\end{array}$ & Odds ratio & $95 \% \mathrm{Cl}$ & $P$ value \\
\hline \multicolumn{6}{|l|}{ Gender } \\
\hline Men & $76(43.67)$ & $213(62.28)$ & Referent & & \\
\hline Women & $98(56.33)$ & $129(37.72)$ & 2.13 & $1.47-3.09$ & $<0.001$ \\
\hline \multicolumn{6}{|l|}{ Age } \\
\hline $35-45$ years & $53(30.46)$ & $99(28.25)$ & Referent & & \\
\hline $46-55$ years & $68(39.08)$ & $169(49.41)$ & 0.75 & $0.49-1.16$ & 0.24 \\
\hline $56-65$ years & $53(30.46)$ & $74(21.64)$ & 1.34 & $0.82-2.17$ & 0.29 \\
\hline \multicolumn{6}{|l|}{ Marital Status } \\
\hline Single & 27 (15.53) & $56(16.37)$ & Referent & & \\
\hline Married & $93(53.44)$ & $223(65.22)$ & 0.86 & $0.51-1.45$ & 0.68 \\
\hline Widow & $30(17.24)$ & $47(13.74)$ & 1.32 & $0.69-2.53$ & 0.50 \\
\hline Divorced / Separated & $24(13.29)$ & $16(4.67)$ & 3.11 & $1.42-6.80$ & 0.007 \\
\hline \multicolumn{6}{|l|}{ Education Level } \\
\hline Matriculation & $49(28.16)$ & $101(29.53)$ & Referent & & \\
\hline Secondary & $87(50.00)$ & $142(41.52)$ & 1.26 & $0.82-1.95$ & 0.34 \\
\hline Graduation and above & $38(21.84)$ & $99(28.95)$ & 0.79 & $0.48-1.31$ & 0.44 \\
\hline \multicolumn{6}{|l|}{ Socio-economic Status } \\
\hline High income & $57(32.75)$ & $124(36.25)$ & Referent & & \\
\hline Middle income & 79 (45.42) & $121(35.38)$ & 1.42 & $0.93-2.17$ & 0.128 \\
\hline Low income & $38(21.83)$ & $97(28.37)$ & 0.85 & $0.52-1.39$ & 0.605 \\
\hline & & & & & (Continued) \\
\hline
\end{tabular}




\begin{tabular}{|c|c|c|c|c|c|}
\hline \multicolumn{6}{|c|}{ Diabetic subjects $(N=516)$} \\
\hline Variables & $\begin{array}{c}\text { Impaired cognition } \\
N(\%) \\
174(33.73)\end{array}$ & $\begin{array}{c}\text { Normal cognition } \\
N(\%) \\
342(66.27)\end{array}$ & Odds ratio & $95 \% \mathrm{Cl}$ & $P$ value \\
\hline \multicolumn{6}{|l|}{ Physical Activity } \\
\hline Active & $43(24.73)$ & $164(47.95)$ & Referent & & \\
\hline Sedentary & $131(75.28)$ & $178(52.04)$ & 2.81 & $1.87-4.21$ & 0.001 \\
\hline \multicolumn{6}{|l|}{ Smoking } \\
\hline Non smoking & $51(29.31)$ & $158(46.19)$ & Referent & & \\
\hline Smoking & $74(42.52)$ & $84(24.56)$ & 2.73 & $1.75-4.26$ & $<0.001$ \\
\hline Ex-smoking & $49(28.16)$ & $100(29.25)$ & 1.52 & $0.95-2.42$ & 0.100 \\
\hline \multicolumn{6}{|l|}{ Alcohol Drinking } \\
\hline Non Drinkers & $28(16.09)$ & $100(29.25)$ & Referent & & \\
\hline Drinkers & $131(75.28)$ & $178(52.04)$ & 6.00 & $3.62-9.93$ & $<0.001$ \\
\hline Ex-drinkers & $15(8.63)$ & $64(18.71)$ & 0.84 & $0.42-1.68$ & 0.75 \\
\hline \multicolumn{6}{|l|}{ Blood Pressure: SBP } \\
\hline$<120 \mathrm{mmHg}$ & $62(35.64)$ & $203(59.35)$ & Referent & & \\
\hline$>120 \mathrm{mmHg}$ & $112(64.36)$ & $139(40.65)$ & 2.64 & $1.81-3.85$ & 0.001 \\
\hline \multicolumn{6}{|l|}{ Blood Pressure: DBP } \\
\hline$<80 \mathrm{mmHg}$ & 69 (39.65) & $184(53.81)$ & Referent & & \\
\hline$>80 \mathrm{mmHg}$ & $105(60.35)$ & $158(46.19)$ & 1.77 & $1.22-2.57$ & 0.003 \\
\hline \multicolumn{6}{|l|}{ Total Cholesterol } \\
\hline$<200 \mathrm{mg} / \mathrm{dl}$ & $119(68.39)$ & $232(67.84)$ & Referent & & \\
\hline$>200 \mathrm{mg} / \mathrm{dl}$ & $55(31.61)$ & $110(32.16)$ & 0.97 & $0.66-1.44$ & 0.98 \\
\hline \multicolumn{6}{|l|}{ Low Density Lipoprotein } \\
\hline$<100 \mathrm{mg} / \mathrm{dl}$ & $123(70.68)$ & $219(64.04)$ & Referent & & \\
\hline$>100 \mathrm{mg} / \mathrm{dl}$ & $51(29.32)$ & $123(35.96)$ & 0.74 & $0.50-1.09$ & 0.16 \\
\hline \multicolumn{6}{|l|}{ Triglycerides } \\
\hline$<150 \mathrm{mg} / \mathrm{dl}$ & $49(28.16)$ & $151(44.16)$ & Referent & & \\
\hline$>150 \mathrm{mg} / \mathrm{dl}$ & $125(71.84)$ & $191(55.84)$ & 2.02 & $1.36-2.99$ & 0.001 \\
\hline \multicolumn{6}{|l|}{ High Density Lipoprotein } \\
\hline$>40 \mathrm{mg} / \mathrm{dl}$ & $40(22.99)$ & $143(41.82)$ & Referent & & \\
\hline$<40 \mathrm{mg} / \mathrm{dl}$ & $134(77.01)$ & $199(58.18)$ & 2.41 & $1.59-3.64$ & 0.001 \\
\hline \multicolumn{6}{|l|}{ Statin Use } \\
\hline Non-users & $81(46.55)$ & $202(59.06)$ & Referent & & \\
\hline Users & $93(53.45)$ & $140(40.94)$ & 1.66 & $1.15-2.34$ & 0.009 \\
\hline \multicolumn{6}{|l|}{$\mathrm{BMI}\left(\mathrm{kg} \cdot \mathrm{m}^{2}\right)$} \\
\hline$<18.4$ & $8(4.59)$ & 14 (4.09) & Referent & & \\
\hline $18.5-24.9$ & $16(9.19)$ & 59 (17.26) & 0.47 & $0.17-1.33$ & 0.25 \\
\hline $25-29.9$ & $74(42.52)$ & $211(61.69)$ & 0.61 & $0.25-1.52$ & 0.42 \\
\hline $30-34.9$ & $42(24.16)$ & $33(9.66)$ & 2.23 & $0.84-5.92$ & 0.17 \\
\hline $35-39.9$ & $25(14.36)$ & $19(5.55)$ & 2.30 & $0.80-6.61$ & 0.19 \\
\hline$>40$ & $9(5.18)$ & $6(1.75)$ & 2.63 & $0.68-10.12$ & 0.28 \\
\hline WHR in Males $(N=289)$ & $(n=76)$ & $(n=213)$ & & & \\
\hline$<90 \mathrm{~cm}$ & $22(12.64))$ & $123(35.96)$ & Referent & & \\
\hline$>90 \mathrm{~cm}$ & $54(31.03)$ & $90(26.31)$ & 3.35 & $1.91-5.90$ & $<0.001$ \\
\hline WHR in Females $(N=227)$ & $(n=98)$ & $(n=129)$ & & & \\
\hline$<80 \mathrm{~cm}$ & $25(17.52)$ & $75(21.92)$ & Referent & & \\
\hline$>80 \mathrm{~cm}$ & 73 (41.95) & $54(15.78)$ & 4.06 & $2.29-7.19$ & $<0.001$ \\
\hline \multicolumn{6}{|l|}{ Glucose Level } \\
\hline$<125 \mathrm{mg} / \mathrm{dl}$ & $75(43.11)$ & $194(56.72)$ & Referent & & \\
\hline$>125 \mathrm{mg} / \mathrm{dl}$ & 99 (56.89) & $148(43.28)$ & 1.73 & $1.20-2.50$ & 0.005 \\
\hline \multicolumn{6}{|l|}{ Duration of Diabetes } \\
\hline$<2$ years & $17(9.77)$ & $96(28.07)$ & Referent & & \\
\hline $2-5$ years & $73(41.96)$ & $194(56.72)$ & 2.12 & $1.19-3.80$ & 0.001 \\
\hline $6-9$ years & $52(29.88)$ & $41(11.98)$ & 7.16 & $3.71-13.84$ & 0.001 \\
\hline$>10$ years & $32(18.39)$ & $11(3.23)$ & 16.43 & $6.97-38.72$ & 0.001 \\
\hline
\end{tabular}

impairment than men (odds ratio $[\mathrm{OR}]=2.13,95 \%$ confidence interval [95\% CI]: 1.47-3.09, $P<0.001$ ). Subjects with sedentary life style $(O R=2.81,95 \%$ CI: 1.87-4.21, $P=0.001$ ), divorced, or separated women $(\mathrm{OR}=3.11,95 \% \mathrm{CI}: 1.42-6.80, \mathrm{P}=0.007)$, smoking $(\mathrm{OR}$
$=2.73,95 \%$ CI: 1.75-4.26, $P<0.001)$, drinking alcohol $(\mathrm{OR}=6.00,95 \% \mathrm{CI}: 3.62-9.93, P<0.001), \mathrm{SBP}(>120$ $\mathrm{mmHg})(\mathrm{OR}=2.64,95 \% \mathrm{CI}: 1.81-3.85, P=0.001)$, diastolic blood pressure $(>80 \mathrm{mmHg})(\mathrm{OR}=1.77,95 \%$ CI: $1.22-2.57, P=0.003)$, triglycerides $(>150 \mathrm{mg} / \mathrm{dl})$ 
$(\mathrm{OR}=2.02,95 \% \mathrm{CI}: 1.36-2.99, \mathrm{P}=0.001)$, high-density lipoprotein $(<40 \mathrm{mg} / \mathrm{dl})(\mathrm{OR}=2.41,95 \% \mathrm{CI}: 1.59-3.64$, $P=0.001)$, statin use $(\mathrm{OR}=1.66,95 \% \mathrm{CI}: 1.15-2.34$, $P=0.009)$, glucose levels $(>125 \mathrm{mg} / \mathrm{dl})(\mathrm{OR}=1.73,95 \%$ CI: $1.20-2.50, P=0.005)$, and duration of diabetes starting from 2 to 10 years and more than 10 years $(P=0.001)$ were having higher chances of cognitive impairment.

Multivariate backward stepwise regression analysis was done to identify variables which were independently associated with cognitive decline [Table 2]. Being a woman $(\mathrm{OR}=2.00,95 \% \mathrm{CI}: 1.25-3.20, P=0.004)$, glucose levels $>125 \mathrm{mg} / \mathrm{dl}(\mathrm{OR}=1.73,95 \% \mathrm{CI}: 1.15-2.61, P=0.008)$, and SBP $>120 \mathrm{mmHg}(\mathrm{OR}=3.70,95 \% \mathrm{CI}: 2.40-5.60$, $P<0.001)$ emerged as independent predictors of cognitive decline. Sedentary life style $(\mathrm{OR}=2.32,95 \% \mathrm{CI}: 1.07-5.08$, $P=0.034)$ and duration of diabetes $>10$ years $(O R=4.34$, 95\% CI: 2.57-7.29, $P<0.001)$ also conferred substantial risk of cognitive impairment independently.

\section{DISCUSSION}

The present study examined the prevalence and predictors of neurocognitive impairment in T2DM patients of Punjab. This is the first study from this region which revealed that the prevalence of cognitive impairment is $33.73 \%$ in diabetic population. Being a diabetic woman is an independent risk factor for neurocognitive impairment which doubles the risk $(\mathrm{OR}=2.13,95 \% \mathrm{CI}: 1.47-3.09$, $P<0.001)$ as compared to man. This inference has been corroborated by some studies, ${ }^{[18,19]}$ and one study reported the risk of cognitive impairment even higher (3.75 times) in women. ${ }^{[20]}$ The prevalence of neurocognitive impairment in T2DM has been scarcely examined in India. One study from Jaipur $^{[21]}$ has shown that the prevalence of neurocognitive impairment in T2DM patients is $48 \%$, however, data from other regions have shown that cognitive decline in T2DM patients ranges from $3 \%$ to $23 \% \cdot{ }^{[22,23]}$ The prevalence rates of cognitive impairment may vary depending on the sampling procedure and diagnostic criteria. ${ }^{[24]}$ Some of the reasons for higher prevalence of cognitive impairment in T2DM

\begin{tabular}{|c|c|c|c|c|}
\hline Variables & $\beta \pm S E$ & OR & $95 \% \mathrm{Cl}$ & $\boldsymbol{P}$ \\
\hline Being a diabetic woman & $0.69 \pm 2.38$ & 2.00 & $1.25-3.20$ & 0.004 \\
\hline Glucose levels $>125 \mathrm{mg} / \mathrm{dl}$ & $0.55 \pm 0.21$ & 1.73 & $1.15-2.61$ & 0.008 \\
\hline $\begin{array}{l}\text { Systolic Blood Pressure } \\
>120 \mathrm{mmHg}\end{array}$ & $1.31 \pm 0.21$ & 3.70 & $2.40-5.60$ & $<0.001$ \\
\hline Sedentary Life Style & $0.84 \pm 0.40$ & 2.32 & $1.07-5.08$ & 0.034 \\
\hline $\begin{array}{l}\text { Duration of Diabetes } \\
>10 \text { years }\end{array}$ & $1.47 \pm 0.26$ & 4.34 & $2.57-7.29$ & $<0.001$ \\
\hline
\end{tabular}

patients in the present study are, first of all, the diabetic OPDs of GMCH, Patiala, primarily caters to referred cases of severe form of diabetes. About $18 \%$ of the subjects in the present study have more than 10 years of diabetes, which may impinge upon the prevalence of cognitive impairment. Second, MMSE $<23$ criteria used in the present study also included subjects having borderline cognitive impairment (19-23 scores). Such borderline subjects may also have supplemented the prevalence in the present study. Other tests (TMT-A and TMT-B) also identify neurocognition in those patients, and Cronbach's statistics in the present study $(\alpha=0.82)$ ruled out any internal inconsistency.

The relationship of T2DM and cognitive decline is very intricate as some unforeseen underlying mechanism targeting neurodegeneration and vascular factors may also participate. Moreover, some studies have largely ignored the adjustment of the effect of risk variables in the analysis, however after adjusting the confounding effect in the backward step wise regression analyses in the present study, subjects having glucose levels $>125 \mathrm{mmHg}$ are at 1.73 times higher risk of developing impairment in neurocognition. This result is in agreement with several studies, ${ }^{[3,22,25-30]}$ however, few reports including Rancho Bernardo cohort study found no association of diabetes with neurocognitive decline. ${ }^{[31]}$ Coker and Shumaker ${ }^{[25]}$ compiled 32 studies which investigated the performance of neuropsychological tests in T2DM patients. Out of these, $67 \%$ (twenty studies) reported a positive association of diabetes with poor performance on neuropsychological tests. Another report has examined the relationship of impaired fasting glucose and neurocognition as the determinant of dementia in older women. ${ }^{[26]}$ In a 4-year randomized trial of raloxifene use, it has been observed that after adjusting the effect of race, education, and co-existing depression, women show severe form of cognitive decline $(P=0.001)$. Similarly, another cross-sectional study on older men highlighted that higher insulin levels and glucose intolerance are significantly associated with lower MMSE scores. ${ }^{[27]}$ Another study compiling the results of ten population-based reports on the association of T2DM and domain-specific neurocognition has revealed a substantial influence of diabetes on neurocognition impairment which may lead to the development of dementia. ${ }^{[22]}$ In a longitudinal cohort study by Luchsinger et al. ${ }^{[3]}$ diabetes is found to be a significant risk factor for all causes of mild cognitive impairment after adjustment for all risk covariates. The association of diabetes with nonamnestic mild cognitive impairment is attenuated after adjustment with vascular risk factors and socio-economic status. The age, gene/environment susceptibility in Reykjavik study has demonstrated that after adjusting the effects of demographic 
and health factors, persons with diabetes show poor performance in processing speed and executive functions. ${ }^{[4]}$ The action to control cardiovascular risk in diabetes-memory in diabetes trial showed statistically significant association between $\mathrm{A} 1 \mathrm{C}$ levels and four cognitive tests after adjusting age and other risk determinants. ${ }^{[28]}$ In the investigation for the relationship of diabetes and cognitive impairment in Iranian population, Ebady et al. ${ }^{[29]}$ documented that diabetes is significantly associated with lower MMSE scores $(\mathrm{OR}=1.9,95 \% \mathrm{CI}: 1.01-3.6, P=0.001)$, which is significantly correlated with duration and quality of diabetes. To understand the modifiers of cognitive function and brain structure in T2DM, it has been observed that subjects with T2DM have reduced hippocampal and prefrontal volumes, verbal declarative memory deficit, and impaired HPA axis feedback regulation. ${ }^{[30]}$

A 20-year follow-up atherosclerosis risk in communities for cognitive change ${ }^{[32]}$ has shown that midlife hypertension, especially higher SBP is highly associated with cognitive decline. Another report concluded that SBP and heart rate independently influence the development of cognitive decline, incident cognitive dysfunction, and cognitive deterioration in high-risk patients with atherosclerosis and diabetes. ${ }^{[33]} \mathrm{In}$ the present study also, diabetic subjects having $>120 \mathrm{mmHg}$ of SBP had 3.70 times higher risk of neurocognitive decline in comparison to nondiabetic subjects.

Another risk factor that independently influenced cognition in the present study is sedentary life style. T2DM patients living sedentary life style have 2 -fold higher risk of neurocognitive impairment than their active counterparts. This finding is in agreement with other studies which have shown that sedentary life style is the hallmark for neurocognitive impairment. ${ }^{[34,35]}$

Duration of diabetes has been observed to influence neurocognition very strongly. Considerable derangements of neurocognition in T2DM patients, especially among older women have been examined. ${ }^{[36]}$ In this longitudinal study, unfavorable cognitive performance has been shown in diabetic subjects over 4 years compared with subjects who had normal glucose levels. ${ }^{[37]}$ It has been revealed that patients diagnosed for diabetes from the last 5 years perform poor for domain-specific cognition such as logical memory and word fluency in comparison to those who are diagnosed lately. ${ }^{[5]}$ A report from Hyderabad, Telangana, India, shows that subjects having duration of diabetes $>5$ years show increased P300 latencies (cognitive dysfunction), a marker of speed of neural events related to attention and short-term memory. ${ }^{[38]}$ Similarly, another study reported that negative correlation exists $(r=-0.408$, $P=0.001)$ between MMSE scores and duration of diabetes in Iranian population. ${ }^{[32]}$ In the present study, diabetic subjects who have duration of diabetes $>10$ years are at 4.34 times higher risk of cognitive impairment.

\section{Limitations}

Some potential limitations of the present study may have influenced the results. First, MMSE scoring to identify neurocognition can be influenced by age and education. Although present study was well matched for these two variables $(P>0.05)$ and other tests involved for diagnosing cognitive decline show significant matching of reliability index (Cronbach's $\alpha=0.82$ ) with MMSE, residual confounding for timed elements of memory and executive functions may have remained to be exposed as MMSE is considered to be less sensitive for them. Second, notwithstanding our study attained considerable power to detect differences, the number of diabetic subjects according to gender in the present study are relatively less, so the implications need caution; more studies involving large cohorts are required to substantiate our key findings.

\section{CONCLUSIONS}

The present study shows that majority of the T2DM patients remain undiagnosed for neurocognition during the course of their life. Cognitive decline in diabetes is independently influenced by risk variables such as being a women, $\mathrm{SBP}>120 \mathrm{mmHg}$, sedentary life style, glucose levels $>125 \mathrm{mg} / \mathrm{dl}$, and duration of diabetes $>10$ years. Higher prevalence of cognitive decline in this region is alarming, and results of the present study suggest that every diabetic subject should be examined for cognition so that future imperative sequels of T2DM, especially neurodegeneration and vascular dementia may be tackled effectively.

Financial support and sponsorship

The grant for major research project sanctioned to PPS by University Grants Commission (F. No. 42-48/2013) is gratefully acknowledged.

Conflicts of interest

There are no conflicts of interest.

\section{REFERENCES}

1. Singh P, Khullar S, Singh M, Kaur G, Mastana S. Diabetes to cardiovascular disease: Is depression the potential missing link? Med Hypotheses 2015;84:370-8.

2. Awad N, Gagnon M, Messier C. The relationship between impaired glucose tolerance, type 2 diabetes, and cognitive function. J Clin Exp Neuropsychol 2004;26:1044-80.

3. Luchsinger JA, Reitz C, Patel B, Tang MX, Manly JJ, Mayeux R. Relation of diabetes to mild cognitive impairment. Arch Neurol 2007;64:570-5.

4. Saczynski JS, Jónsdóttir MK, Garcia ME, Jonsson PV, Peila R, 
Eiriksdottir G, et al. Cognitive impairment: An increasingly important complication of type 2 diabetes: The age, gene/ environment susceptibility - Reykjavik study. Am J Epidemiol 2008;168:1132-9.

5. Elias PK, Elias MF, D'Agostino RB, Cupples LA, Wilson PW, Silbershatz $\mathrm{H}$, et al. NIDDM and blood pressure as risk factors for poor cognitive performance. The Framingham Study. Diabetes Care 1997;20:1388-95.

6. Stewart R, Liolitsa D. Type 2 diabetes mellitus, cognitive impairment and dementia. Diabet Med 1999;16:93-112.

7. Strachan MW, Deary IJ, Ewing FM, Frier BM. Is type II diabetes associated with an increased risk of cognitive dysfunction? A critical review of published studies. Diabetes Care 1997;20:438-45.

8. Ott A, Stolk RP, Hofman A, van Harskamp F, Grobbee DE, Breteler MM. Association of diabetes mellitus and dementia: The Rotterdam Study. Diabetologia 1996;39:1392-7.

9. Yoshitake T, Kiyohara Y, Kato I, Ohmura T, Iwamoto H, Nakayama K, et al. Incidence and risk factors of vascular dementia and Alzheimer's disease in a defined elderly Japanese population: The Hisayama Study. Neurology 1995;45:1161-8.

10. Grodstein F, Chen J, Wilson RS, Manson JE. Type 2 diabetes and cognitive function in community-dwelling elderly women. Diabetes Care 2001;24:1060-5.

11. Stegmayr B, Asplund K. Diabetes as a risk factor for stroke. A population perspective. Diabetologia 1995;38:1061-8.

12. de la Monte SM, Wands JR. Alzheimer's disease is type 3 diabetes-evidence reviewed. J Diabetes Sci Technol 2008;2:1101-13.

13. American Diabetes Association. Standards of medical care in diabetes. Diabetes Care 2012;30:S11-63.

14. Folstein MF, Folstein SE, McHugh PR. "Mini-mental state". A practical method for grading the cognitive state of patients for the clinician. J Psychiatr Res 1975;12:189-98.

15. Tsolaki M, lakovidou V, Navrozidou H, Aminta M, Pantazi T, Kazis A. Hindi mental state examination (HMSE) as a screening test for illiterate demented patients. Int J Geriatr Psychiatry 2000;15:662-4.

16. Reitan RM. The validity of the trail making test as an indicator of organic brain damage. Percept Mot Skills 1958;8:271-6.

17. Aggarwal OP, Bhasin SK, Sharma AK, Chhabra P, Aggarwal K, Rajoura OP. A new instrument (scale) for measuring the socioeconomic status of a family: Preliminary study. Indian $\mathrm{J}$ Community Med 2005;30:111-4.

18. Ho SC, Woo J, Sham A, Chan SG, Yu AL. A 3-year follow-up study of social, lifestyle and health predictors of cognitive impairment in a Chinese older cohort. Int J Epidemiol 2001;30:1389-96.

19. Irvine K, Laws KR, Gale TM, Kondel TK. Greater cognitive deterioration in women than men with Alzheimer's disease: A meta analysis. J Clin Exp Neuropsychol 2012;34:989-98.

20. Yu ES, Liu WT, Levy P, Zhang MY, Katzman R, Lung CT, et al. Cognitive impairment among elderly adults in Shanghai, China. J Gerontol 1989;44:S97-106.

21. Solanki RK, Dubey V, Munshi D. Neurocognitive impairment and comorbid depression in patients of diabetes mellitus. Int $\mathrm{J}$ Diabetes Dev Ctries 2009;29:133-8.

22. Allen KV, Frier BM, Strachan MW. The relationship between type 2 diabetes and cognitive dysfunction: Longitudinal studies and their methodological limitations. Eur J Pharmacol 2004;490:169-75.

23. Ryan CM, Freed MI, Rood JA, Cobitz AR, Waterhouse BR,
Strachan MW. Improving metabolic control leads to better working memory in adults with type 2 diabetes. Diabetes Care 2006;29:345-51.

24. Petersen RC, Doody R, Kurz A, Mohs RC, Morris JC, Rabins PV, et al. Current concepts in mild cognitive impairment. Arch Neurol 2001;58:1985-92.

25. Coker LH, Shumaker SA. Type 2 diabetes mellitus and cognition: An understudied issue in women's health. J Psychosom Res 2003;54:129-39.

26. Yaffe K, Blackwell T, Kanaya AM, Davidowitz N, Barrett-Connor E, Krueger K. Diabetes, impaired fasting glucose, and development of cognitive impairment in older women. Neurology 2004;63:658-63.

27. Kalmijn S, Feskens EJ, Launer LJ, Stijnen T, Kromhout D. Glucose intolerance, hyperinsulinaemia and cognitive function in a general population of elderly men. Diabetologia 1995;38:1096-102.

28. Cukierman-Yaffe T, Gerstein HC, Williamson JD, Lazar RM, Lovato L, Miller ME, et al. Relationship between baseline glycemic control and cognitive function in individuals with type 2 diabetes and other cardiovascular risk factors: The action to control cardiovascular risk in diabetes-memory in diabetes (ACCORD-MIND) trial. Diabetes Care 2009;32:221-6.

29. Ebady SA, Arami MA, Shafigh MH. Investigation on the relationship between diabetes mellitus type 2 and cognitive impairment. Diabetes Res Clin Pract 2008;82:305-9.

30. Bruehl H, Wolf OT, Convit A. A blunted cortisol awakening response and hippocampal atrophy in type 2 diabetes mellitus. Psychoneuroendocrinology 2009;34:815-21.

31. Scott RD, Kritz-Silverstein D, Barrett-Connor E, Wiederholt WC. The association of non-insulin-dependent diabetes mellitus and cognitive function in an older cohort. J Am Geriatr Soc 1998;46:1217-22.

32. Gottesman RF, Rawlings AM, Sharrett AR, Albert M, Alonso A, Bandeen-Roche $\mathrm{K}$, et al. Impact of differential attrition on the association of education with cognitive change over 20 years of follow-up: The ARIC neurocognitive study. Am J Epidemiol 2014;179:956-66.

33. Böhm M, Schumacher H, Leong D, Mancia G, Unger T, Schmieder R, et al. Systolic blood pressure variation and mean heart rate is associated with cognitive dysfunction in patients with high cardiovascular risk. Hypertension 2015;65:651-61.

34. Sink KM, Espeland MA, Rushing J, Castro CM, Church TS, Cohen R, et al. The LIFE Cognition Study: Design and baseline characteristics. Clin Interv Aging 2014;9:1425-36.

35. Loprinzi PD, Kane CJ. Exercise and cognitive function: A randomized controlled trial examining acute exercise and free-living physical activity and sedentary effects. Mayo Clin Proc 2015;90:450-60.

36. Gregg EW, Yaffe K, Cauley JA, Rolka DB, Blackwell TL, Narayan KM, et al. Is diabetes associated with cognitive impairment and cognitive decline among older women? Study of Osteoporotic Fractures Research Group. Arch Intern Med 2000;160:174-80.

37. Fontbonne A, Berr C, Ducimetière P, Alpérovitch $A$. Changes in cognitive abilities over a 4-year period are unfavorably affected in elderly diabetic subjects: Results of the epidemiology of vascular aging study. Diabetes Care 2001;24:366-70.

38. Hazari MA, Reddy BR, Uzma N, Kumar BS. Cognitive impairment in type 2 diabetes mellitus. Int J Diabetes Mellit 2015;3:19-24. 